\title{
openheart Excess short-term mortality in women after isolated coronary artery bypass graft surgery
}

\author{
Giovanni Filardo, ${ }^{1}$ Baron L Hamman, ${ }^{2}$ Benjamin D Pollock, ${ }^{1}$ Briget da Graca, ${ }^{1}$ \\ Danielle M Sass, ${ }^{1}$ Teresa K Phan, ${ }^{1}$ James Edgerton, ${ }^{3}$ Syma L Prince, ${ }^{4}$ \\ W Steves Ring ${ }^{5}$
}

To cite: Filardo G, Hamman BL, Pollock BD, et al. Excess short-term mortality in women after isolated coronary artery bypass graft surgery. Open Heart 2016;3:e000386. doi:10.1136/openhrt-2015000386

Received 11 December 2015 Revised 21 January 2016 Accepted 14 February 2016

${ }^{1}$ Department of Epidemiology, Office of the Chief Quality Officer, Baylor Scott \& White Health, Dallas, Texas, USA

${ }^{2}$ Department of Cardiothoracic Surgery, Baylor Heart and Vascular Institute, Baylor University Medical Center, Dallas, Texas, USA

${ }^{3}$ The Heart Hospital Baylor, Plano, Texas, USA

${ }^{4}$ Cardiopulmonary Research Science \& Technology Institute, Dallas, Texas, USA ${ }^{5}$ Department of

Cardiothoracic Surgery, UT Southwestern Medical Center, Dallas, Texas, USA

Correspondence to Dr Giovanni Filardo; giovanfi@baylorhealth.edu

\section{ABSTRACT}

Objective: Female sex is considered a risk factor for adverse outcomes following isolated coronary artery bypass graft (CABG) surgery. We assessed the association between sex and short-term mortality following isolated CABG, and estimated the 'excess' deaths occurring in women.

Methods: Short-term mortality was investigated in 13327 consecutive isolated CABG patients in North Texas between January 2008 and December 2012. The association between sex and CABG short-term mortality, and the excess deaths among women were assessed via a propensity-adjusted (by Society of Thoracic Surgeons-recognised risk factors) generalised estimating equations model approach.

Results: Short-term mortality was significantly higher in women than men (adjusted OR=1.39; 95\% $\mathrm{Cl} 1.04$ to $1.86 ; p=0.027)$. This significantly greater risk translates into 35 'excess' deaths among women included in this study $(>10 \%$ of the total 343 deaths in the study cohort) and into 392 'excess' deaths among the $\sim 40000$ women undergoing isolated CABG in the USA each year.

Conclusions: The higher risk associated with female sex lead to 35 'excess' deaths in women in this study cohort (over $10 \%$ of the total deaths) and to 392 'excess' deaths among women undergoing isolated CABG in the USA each year. Further research is needed to assess the causal mechanisms underlying this sexrelated difference. Results of such work could inform the development and implementation of sex-specific treatment and management strategies to reduce women's mortality following CABG. Based on our results, if such work brought women's short-term mortality into line with men's, total short-term mortality could be reduced by up to $10 \%$.

\section{INTRODUCTION}

Men and women present for coronary artery bypass graft (CABG) surgery with very different profiles: women are generally older and have more significant comorbidities ${ }^{1-5}$ and more urgent/emergent surgery, ${ }^{1}{ }^{3}$ but have less extensive disease patterns requiring less

\section{KEY QUESTIONS}

What is already known about this subject?

- Previous studies comparing outcomes for men and women following coronary artery bypass graft (CABG) surgery show inconsistent and contradictory results, ranging from higher mortality among women, to a protective effect of female sex. Among those reporting higher mortality for women, inconsistent conclusions have been reached as to whether it stems from risks inherent to their sex or from worse preoperative risk profiles.

What does this study add?

- This study provides evidence that female sex itself is associated with higher risk of mortality in CABG. Based on this higher risk, it estimates that an 'excess' 392 deaths occur among women undergoing isolated CABG in the USA each year.

How might this impact on clinical practice?

- These results show that a meaningful number of women's lives will be impacted by research aimed at uncovering the causes underlying their higher risk of CABG mortality and developing sex-specific management and treatment approaches that offer them an equivalent chance of survival to men.

revascularisation ${ }^{1-3}$ and shorter cross clamp times. ${ }^{1}$ Despite female sex being among the risk factors included in both the Society of Thoracic Surgeons (STS ${ }^{6}$ and EuroSCORE risk models, ${ }^{78}$ the question of whether-and how-sex independently impacts outcomes following CABG continues to be raised, with large, recent studies that take patient risk factors into account showing contradictory results. ${ }^{1359}$ Resolving this question is important because, if female sex is an independent risk factor for poorer outcomes, sex-specific strategies for treatment and management may need to be developed to offer men and 
women in need of surgical revascularisation equivalent chances and qualities of survival. We present the comparison of short-term mortality following isolated CABG in men versus women, and estimate the 'excess' deaths associated with female sex, using a large cohort $(n=13$ 327) of consecutive patients in North Texas.

\section{METHODS}

This multicentre, retrospective, cohort study included all consecutive patients who underwent isolated CABG from January 2008 to December 2012 in a hospital participating in the Texas Quality Institute (TQI). Through TQI, 32 of the 34 cardiac surgery programmes in North Texas region share the data submitted to the STS National Adult Cardiac Surgery Database ${ }^{6}$ with the Dallas-Fort Worth Hospital Council, where they are combined into a single registry and paired with administrative/claims data, enabling long-term comparative effectiveness, costeffectiveness and quality outcomes research. ${ }^{10} 11$

After excluding patients with previous valve surgery $(\mathrm{n}=28)$, preoperative endocarditis $(\mathrm{n}=13)$ and/or a ventricular assist device $(\mathrm{n}=0)$, the final study cohort consisted of 13327 consecutive isolated CABG patients.

Means, SDs and percentages were calculated to describe the study cohort. Differences in demographic and clinical details were assessed with a Wilcoxon test for continuous factors and a $\chi^{2}$ test for categorical factors. A Bonferroni correction was applied to account for multiplicity.

The STS definition for operative mortality was applied for short-term mortality: the patient died during the operation, during the subsequent hospital stay, or within 30 days from surgery. To assess the adjusted association between sex and post-CABG short-term mortality, so that the excess deaths associated with female sex could be estimated, we used a propensity-adjusted generalised estimating equations model approach. ${ }^{12}{ }^{13}$ The propensity adjustment accounted for risk factors recognised by the STS; ${ }^{6}$ these factors are listed in table 1 . A restricted cubic spline function with five knots was used to fit the propensity score as an independent variable in a generalised estimating equations model with short-term mortality as the dependent variable and sex as the independent variable. Multiple imputation of all covariates used in the propensity model was done by Markov Chain Monte Carlo simulation, ${ }^{14} 15$ to account for missing data (preoperative atrial fibrillation: $29.7 \%$ missing, ejection fraction: $7.3 \%$ missing and left main disease: $0.4 \%$ missing). A total of 10 imputed data sets were created using 200 burn-in iterations. The point estimates and variances from the imputed data sets were pooled using standard methods developed by Rubin. ${ }^{16-18}$ All continuous variables in the propensity model were fitted using restricted cubic splines with five knots. ${ }^{13} 19$ Effect modification between sex and all the risk factors listed in table 1 were tested. Where significant interactions $(\mathrm{p}<0.05)$ were identified, sex-stratified ORs and CIs were estimated.
The excess deaths associated with female sex (ie, the number of women who would not die if women's risk of operative mortality was the same as men's) were calculated by applying the estimated adjusted risk difference between men and women to:

1. The total number of isolated CABGs performed on women in the present study (excess deaths in women in this study cohort); and

2. To the number of isolated CABG procedures performed on women in the USA each year (reported for the most recent full year in the STS Adult Cardiac Surgery database) ${ }^{20}$ (annual excess deaths in women undergoing CABG in the USA).

All analyses were conducted using SAS V.9.3, SAS Institute Inc, Cary, North Carolina, USA. The study protocol was approved by the Baylor Research Institute Institutional Review Board, and was granted a waiver for informed consent.

\section{RESULTS}

There were 343 deaths (2.6\%) in the study cohort; among men, there were 206 (2.1\%) deaths, while among women, there were 137 (3.9\%). Patients' clinical and non-clinical details are presented in table 1 . Both the unadjusted and adjusted (for recognised STS risk factors for mortality) analyses showed that women were significantly more likely to experience short-term mortality than men (OR unadjusted $=1.90 ; 95 \%$ CI 1.52 to 2.36; OR adjusted $=1.39$; $95 \%$ CI 1.04 to 1.86 ; figure 1 ). Interaction with sex was significant only for preoperative intra-aortic balloon pump (see table 1).

Applying the estimated adjusted risk difference observed in our study population $(3.36 \%$ for women-2.38\% for men) shows that the higher risk associated with female sex leads to 35 'excess' operative deaths among the women included in our study (constituting $>10 \%$ of the total deaths in the study cohort). In 2013, 147600 isolated CABG surgeries were reported nationwide in the STS Adult Cardiac Surgery Database. ${ }^{20}$ Approximately, 40000 of these procedures were performed in women. ${ }^{6}$ Applying the risk-adjusted difference estimates from our study to these numbers, 392 'excess' deaths among women undergoing isolated CABG can be expected each year.

\section{DISCUSSION}

The results of our study support a growing body of evidence indicating greater risk of short-term mortality following isolated CABG for women than men, even after adjusting for the worse preoperative clinical profiles and older age at surgery that are typical of women undergoing CABG. ${ }^{9}{ }^{21-24}$ More importantly, it shows that this significantly greater risk of short-term mortality in women translates into 35 'excess' deaths among women in the present study, and to 392 'excess' deaths among the approximately 40000 women undergoing isolated CABG in the USA each year. These 'excess' deaths constitute $>10 \%$ of the total deaths in our study cohort, suggesting 
Table 1 STS clinical and non-clinical risk factors by sex

\begin{tabular}{|c|c|c|c|c|}
\hline \multirow[b]{2}{*}{ Characteristic } & \multicolumn{3}{|l|}{ Sex } & \multirow{2}{*}{$\begin{array}{l}\text { Interaction with sex } \\
\text { p Valuet }\end{array}$} \\
\hline & Male $(n=9818,73.7 \%)$ & Female $(n=3509,26.3 \%)$ & p Value* & \\
\hline \multicolumn{5}{|l|}{ Demographics } \\
\hline Age $\ddagger$ & $64.0 \pm 10.2$ & $65.9 \pm 10.9$ & $<0.003$ & 0.889 \\
\hline Body surface area $\ddagger\left(\mathrm{m}^{2}\right)$ & $2.1 \pm 0.2$ & $1.8 \pm 0.2$ & $<0.003$ & 0.793 \\
\hline Race & & & $<0.003$ & 0.797 \\
\hline White & $79.5 \%$ & $74.5 \%$ & & \\
\hline Black & $5.8 \%$ & $11.7 \%$ & & \\
\hline Hispanic & $9.0 \%$ & $8.9 \%$ & & \\
\hline Other/unknown & $5.7 \%$ & $4.9 \%$ & & \\
\hline \multicolumn{5}{|l|}{ Risk factors } \\
\hline Diabetes mellitus & $41.1 \%$ & $50.0 \%$ & $<0.003$ & 0.950 \\
\hline Renal failure (dialysis) & $2.5 \%$ & $3.4 \%$ & 0.108 & 0.829 \\
\hline Creatinine $\neq(\mathrm{mg} / \mathrm{dL})$ & $1.3 \pm 1.0$ & $1.2 \pm 1.1$ & $<0.003$ & 0.887 \\
\hline Chronic lung disease & $13.7 \%$ & $18.3 \%$ & $<0.003$ & 0.316 \\
\hline Hypertension & $85.5 \%$ & $89.6 \%$ & $<0.003$ & 0.739 \\
\hline Cerebrovascular disease & $11.7 \%$ & $18.4 \%$ & $<0.003$ & 0.173 \\
\hline Time from last MI to surgery & & & 0.062 & 0.327 \\
\hline None & $50.9 \%$ & $54.4 \%$ & & \\
\hline$\leq 6 \mathrm{~h}$ & $1.3 \%$ & $1.5 \%$ & & \\
\hline$>6$ and $<24 \mathrm{~h}$ & $2.6 \%$ & $2.5 \%$ & & \\
\hline$\geq 24 \mathrm{~h}$ & $45.2 \%$ & $41.7 \%$ & & \\
\hline Tobacco use & & & $>0.99$ & 0.806 \\
\hline Never & $72.7 \%$ & $73.7 \%$ & & \\
\hline Previous & $21.1 \%$ & $20.4 \%$ & & \\
\hline Current & $6.2 \%$ & $6.0 \%$ & & \\
\hline \multicolumn{5}{|l|}{ Previous interventions } \\
\hline Previous $\mathrm{PCl}$ & $30.3 \%$ & $27.9 \%$ & 0.150 & 0.481 \\
\hline Previous CABG & $4.5 \%$ & $3.8 \%$ & $>0.99$ & 0.310 \\
\hline \multicolumn{5}{|l|}{ Preoperative cardiac status } \\
\hline Preoperative angina (w/in 2 weeks) & $24.4 \%$ & $24.1 \%$ & $>0.99$ & 0.882 \\
\hline $\begin{array}{l}\text { Preoperative atrial fibrillation } \\
(29 \% \text { missing })\end{array}$ & $9.4 \%$ & $8.4 \%$ & $>0.99$ & 0.962 \\
\hline \multicolumn{5}{|l|}{ Haemodynamics and catheterisation } \\
\hline Ejection fraction $\ddagger$ (7\% missing) & $49.6 \% \pm 13.4 \%$ & $53.1 \% \pm 13.0 \%$ & $<0.003$ & 0.680 \\
\hline Left main disease & $32.5 \%$ & $32.3 \%$ & $>0.99$ & 0.119 \\
\hline \multicolumn{5}{|l|}{ Operative } \\
\hline Status & & & 0.042 & 0.885 \\
\hline Elective & $50.4 \%$ & $47.3 \%$ & & \\
\hline Non-elective & $49.7 \%$ & $52.7 \%$ & & \\
\hline Bypass use $\S$ & & & $<0.003$ & \\
\hline Off-pump CABG & $39.5 \%$ & $43.8 \%$ & & NA§ \\
\hline On-pump CABG & $60.6 \%$ & $56.2 \%$ & & \\
\hline Preoperative IABP & $10.9 \%$ & $10.6 \%$ & $>0.99$ & $\begin{array}{l}0.004 \\
\text { Male OR }(95 \% \mathrm{Cl}) \\
=3.8(2.7,5.2) \\
\text { Female OR }(95 \% \mathrm{Cl}) \\
=6.5(4.4,9.6)\end{array}$ \\
\hline Unadjusted short-term mortality & $2.10 \%$ & $3.90 \%$ & $<0.0001$ & NA \\
\hline
\end{tabular}

* $p$ Values using Pearson $\chi^{2}$ and Bonferroni correction.

tp Values using Wald $\chi^{2}$

$\ddagger$ Mean \pm SD with Wilcoxon signed sum-rank test for $p$ value.

$\S$ Not included in the STS risk score; nor in our propensity-adjusted analysis.

CABG, coronary artery bypass graft; Cl, confidence interval; IABP, intra-aortic balloon pump; MI, myocardial infarction; NA, not available; OR, odds ratio; $\mathrm{PCI}$, percutaneous coronary intervention; STS, Society of Thoracic Surgeons.

that identifying strategies to improve women's outcomes could meaningfully improve overall mortality rates for CABG.
The magnitude of the effect of female sex on shortterm mortality (adjusted $\mathrm{OR}=1.39$ ) in our study is similar to that reported in a recent meta-analysis of 
Figure 1 Unadjusted and propensity-adjusted* odds ratio and propensity-adjusted* predicted probabilities for shortterm mortality.
Unadjusted and propensity adjusted ${ }^{*}$ odds ratios for short-term mortality and $\mathbf{9 5 \%}$ confidence intervals

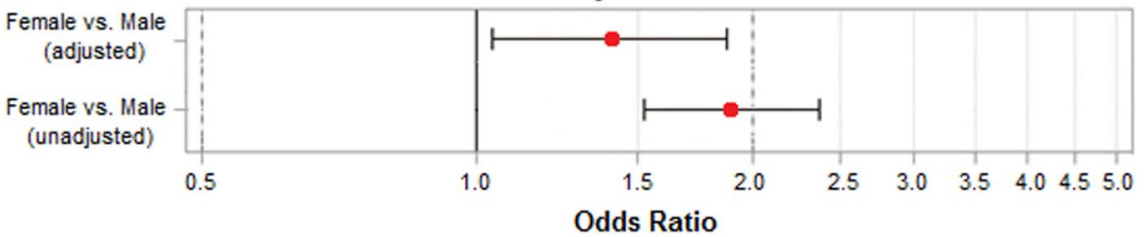

Odds Ratio

Propensity adjusted ${ }^{\star}$ predicted probabilities of

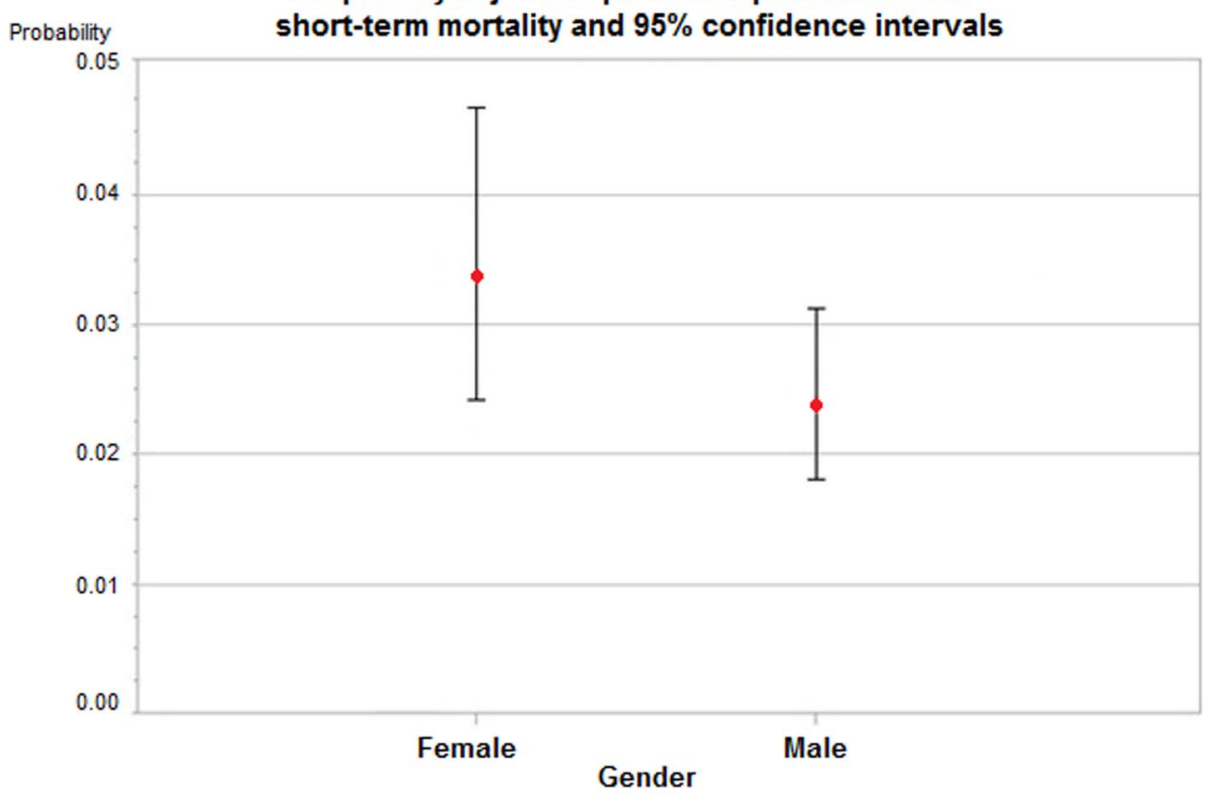

*adjusted by risk factors listed in Table 1 isolated $\mathrm{CABG}$ surgeries when the included studies were limited to the subgroup of four papers that performed propensity matching ( $\mathrm{OR}=1.36 ; 95 \%$ CI 1.04 to 1.78$).^{25}$ Two other studies, a large cohort study ${ }^{5}$ using the STS database and a study encompassing a Californian statewide cohort, ${ }^{9}$ also reported risk-adjusted odds of women's isolated CABG short-term mortality in similar ranges $(\mathrm{OR}=1.39 ; 95 \%$ CI 1.14 to 1.70 and $\mathrm{OR}=1.61$; $95 \%$ CI 1.40 to 1.84 , respectively). In contrast, a recent analysis of 21534 isolated CABG patients across 18 Australian hospitals found that the higher short-term mortality seen in women in the raw data disappeared following adjustment for patient risk factors in multivariate analysis (adjusted in hospital $\mathrm{OR}=0.96$; 95\% CI 0.71 to 1.29; adjusted 30-day $\mathrm{OR}=0.93$; $95 \%$ CI 0.68 to 1.27$){ }^{3}$

It is still unknown what mechanism(s) cause the greater isolated CABG short-term mortality seen in women. Hypotheses include the smaller luminal diameter of coronary arteries (independent of body size) in women, which can increase the difficulty of revascularisation, and the less frequent use of left internal mammary artery grafts and bilateral internal mammary grafts. $^{26-30}$ Other hypotheses include women's more extensive microvascular dysfunction (which the epicardial revascularisation performed in CABG does little to address ${ }^{28}$ ), their more frequent need for postoperative inotropic support and periprocedural blood transfusions, and longer lengths of hospital stay-all of which influence perioperative complications and can therefore affect short-term mortality. ${ }^{28} 3132$ In our study cohort, a significantly greater proportion of women than men underwent off-pump CABG-a technique which previous research has suggested 'disproportionately' benefits women and helps narrow the sex gap inoperative mortality. ${ }^{5} 33$ However, re-running our analysis to adjust for the use of off-pump versus on-pump CABG did not alter our results (OR comparing women vs men $=1.40 ; 95 \%$ CI 1.04 to $1.88 ; \mathrm{p}=0.025)$.

Other studies suggest that increased risk for short-term mortality with female sex is not limited to CABG surgery. There is at least some evidence that female sex may be an independent risk factor for early death following percutaneous coronary intervention, ${ }^{34}$ aortic valve replacement ${ }^{34}$ and mitral valve surgery, ${ }^{35}$ although no conclusive explanations for these sex-based differences have been reached. The under-representation of women in the clinical trials on which current cardiovascular guidelines are based ${ }^{36}$ and resulting extrapolation 
the evidence obtained in men to guide the care provided to women ${ }^{37}$ may play a role in the broader disadvantage women experience.

The use of an observational design is unavoidable when examining the effects of sex, but is inherently unable to establish causality. The propensity-adjustment method used here mitigates this problem by allowing for a quasi-randomised experimental analysis. To minimise the possibility that relevant confounding factors remained unaccounted for, we adjusted for risk factors recognised by the STS. ${ }^{6}$ Importantly, our results are based on a large cohort of patients drawn from 32 of the 34 cardiac surgery programmes in North Texas (covering 7 million people), ${ }^{38}$ and include a representative mix of the predominant racial/ethnic groups in Northern America, making them highly generalisable to the broader population of patients undergoing isolated CABG surgery. The study database is a regional subset of the national STS' Adult Cardiac Database, and so is limited to the data collected for that initiative. As such, that data necessary to examine important questions such as whether sex-based differences in time of death (during surgery vs postsurgery hospitalisation vs postdischarge) and cause of death exist, or whether sex-based differences in extent of coronary artery disease, such as previous research has identified, ${ }^{39}$ contributed to the excess mortality seen in women, were not available.

In conclusion, our results support the hypothesis that women have a greater risk of CABG short-term mortality, independent of pre-existing comorbidities or demographics, than men. While the absolute difference in adjusted risk may seem small for a single patient $(3.36 \%$ for women vs $2.38 \%$ for men in our study population), applying it to the $\sim 40000$ women undergoing isolated CABG procedures in the USA each year, ${ }^{6}{ }^{20}$ it translates into 392 'excess' deaths. Given that the current clinical guidelines simply extrapolate the evidence obtained in men to women, ${ }^{37}$ further research is needed to investigate the causal mechanisms behind the sex-related difference in CABG short-term mortality. The results of such research might inform the development of sexspecific treatment and management approaches that could bring women's risk of short-term mortality when undergoing CABG in line with men's, and meaningfully reduce total short-term mortality rates.

Contributors GF was involved in study concept and design, data analysis and interpretation, drafting the manuscript. BLH, JE and WSR were involved in study conception, data interpretation and revising the manuscript for critical intellectual content. BDP was involved in data analysis, drafting the manuscript. $B d G$ was involved in literature review, data interpretation, drafting the manuscript. DMS and TKP were involved in data collection and management, revising the manuscript for critical intellectual content. SLP was involved in data collection, revising the manuscript for critical intellectual content.

Funding This work was funded in part by the Bradley Family Endowment to the Baylor Health Care System Foundation (Dallas, Texas, USA), The Baylor Health Care System Cardiovascular Research Committee (Dallas, Texas, USA) and the Discovery Foundation (Dallas, Texas, USA).

Competing interests None declared.
Ethics approval Baylor Research Institute Institutional Review Board.

Provenance and peer review Not commissioned; externally peer reviewed.

Data sharing statement Study data will be available to other researchers at their request. Researchers who would like to use data from the published study should submit their requests to GF.

Open Access This is an Open Access article distributed in accordance with the Creative Commons Attribution Non Commercial (CC BY-NC 4.0) license, which permits others to distribute, remix, adapt, build upon this work noncommercially, and license their derivative works on different terms, provided the original work is properly cited and the use is non-commercial. See: http:// creativecommons.org/licenses/by-nc/4.0/

\section{REFERENCES}

1. Al-Alao BS, Parissis H, McGovern E, et al. Gender influence in isolated coronary artery bypass graft surgery: a propensity match score analysis of early outcomes. Gen Thorac Cardiovasc Surg 2012;60:417-24.

2. Sharoni E, Kogan A, Medalion B, et al. Is gender an independent risk factor for coronary bypass grafting? Thorac Cardiovasc Surg 2009;57:204-8.

3. Saxena A, Dinh D, Smith JA, et al. Sex differences in outcomes following isolated coronary artery bypass graft surgery in Australian patients: analysis of the Australasian Society of Cardiac and Thoracic Surgeons cardiac surgery database. Eur J Cardiothorac Surg 2012;41:755-62.

4. Koch CG, Weng YS, Zhou SX, et al. Prevalence of risk factors, and not gender per se, determines short- and long-term survival after coronary artery bypass surgery. J Cardiothorac Vasc Anesth 2003;17:585-93.

5. Puskas JD, Edwards FH, Pappas PA, et al. Off-pump techniques benefit men and women and narrow the disparity in mortality after coronary bypass grafting. Ann Thorac Surg 2007;84:1447-54; discussion 54-6.

6. Shahian DM, O'Brien SM, Filardo G, et al. The Society of Thoracic Surgeons 2008 cardiac surgery risk models: part 1-coronary artery bypass grafting surgery. Ann Thorac Surg 2009;88:S2-22.

7. Nashef SA, Roques F, Michel P, et al. European system for cardiac operative risk evaluation (EuroSCORE). Eur J Cardiothorac Surg 1999;16:9-13.

8. Nashef SA, Roques F, Sharples LD, et al. EuroSCORE II. Eur J Cardiothorac Surg 2012;41:734-44; discussion 44-5.

9. Bukkapatnam RN, Yeo KK, Li Z, et al. Operative mortality in women and men undergoing coronary artery bypass grafting (from the California Coronary Artery Bypass Grafting Outcomes Reporting Program). Am J Cardiol 2010;105:339-42.

10. Jenkins K. Using data to improve healthcare. Translating publicly available data into quality improvement initiatives. J AHIMA 2012;83:44-5

11. DFWHC Foundation. Announcing a New Initiative: "Texas Quality Institute". DFWHC Foundation blog. https://dfwhcfoundation.org/ announcing-a-new-initiativetexas-quality-institute (accessed 15 Jul 2015).

12. D'Agostino RB Jr. Propensity score methods for bias reduction in the comparison of a treatment to a non-randomized control group. Stat Med 1998;17:2265-81.

13. Harrell FE Jr. Regression modeling strategies: with application to linear models, logistic regression, and survival analysis. New York: Springer-Verlag, 2001.

14. Yuan YC. Multiple imputation for missing data: concepts and new developments (version 9.0). Rockville, MD: SAS Institute, Inc., 2003.

15. Schafer JL, Olson MK. Multiple Imputation for multivariate missing-data problems: a data analyst's perspective. Multivariate Behav Res 1998;33:545-71.

16. Rubin DB. Multiple imputation for nonresponse in surveys. New York: Wiley, 1987

17. Rubin DB, Schenker N. Multiple imputation in health-care databases: an overview and some applications. Stat Med 1991;10:585-98.

18. D'Agostino RB Jr. Propensity scores in cardiovascular research. Circulation 2007;115:2340-3.

19. Filardo G, Hamilton C, Hamman B, et al. Categorizing BMI may lead to biased results in studies investigating in-hospital mortality after isolated CABG. J Clin Epidemiol 2007;60:1132-9.

20. The Society of Thoracic Surgeons. Adult Cardiac Surgery Database Executive Summary 10 Years - STS Period Ending 09/30/2014. 
http://www.sts.org/sites/default/files/documents/2014Harvest4_ ExecutiveSummary.pdf (accessed 19 may 2015)

21. Alam M, Lee VV, Elayda MA, et al. Association of gender with morbidity and mortality after isolated coronary artery bypass grafting. A propensity score matched analysis. Int J Cardiol 2013;167:180-4.

22. Naughton C, Feneck RO, Roxburgh J. Early and late predictors of mortality following on-pump coronary artery bypass graft surgery in the elderly as compared to a younger population. Eur J Cardiothorac Surg 2009;36:621-7.

23. Edwards FH, Carey JS, Grover FL, et al. Impact of gender on coronary bypass operative mortality. Ann Thorac Surg 1998;66:125-31.

24. Vaccarino V, Abramson JL, Veledar E, et al. Sex differences in hospital mortality after coronary artery bypass surgery: evidence for a higher mortality in younger women. Circulation 2002;105:1176-81.

25. Alam M, Bandeali SJ, Kayani WT, et al. Comparison by meta-analysis of mortality after isolated coronary artery bypass grafting in women versus men. Am J Cardiol 2013;112:309-17.

26. Gansera B, Gillrath G, Lieber M, et al. Are men treated better than women? Outcome of male versus female patients after CABG using bilateral internal thoracic arteries. Thorac Cardiovasc Surg 2004:52:261-7.

27. Kurlansky PA, Traad EA, Dorman MJ, et al. Bilateral internal mammary artery grafting reverses the negative influence of gender on outcomes of coronary artery bypass grafting surgery. Eur $J$ Cardiothorac Surg 2013;44:54-63.

28. Ouzounian M, Currie ME, Buth KJ, et al. Myocardium at risk is associated with adverse clinical events in women but not in men, after coronary artery bypass grafting. Can J Cardiol 2014;30:808-13.

29. Kim SG, Apple S, Mintz GS, et al. The importance of gender on coronary artery size: in-vivo assessment by intravascular ultrasound. Clin Cardiol 2004;27:291-4.

30. Sheifer SE, Canos MR, Weinfurt KP, et al. Sex differences in coronary artery size assessed by intravascular ultrasound. Am Heart J 2000;139:649-53.
31. Reis SE, Holubkov R, Conrad Smith AJ, et al. Coronary microvascular dysfunction is highly prevalent in women with chest pain in the absence of coronary artery disease: results from the NHLBI WISE study. Am Heart J 2001:141:735-41.

32. Tarakji A, Prasad S, Chedrawy E, et al. Gender disparity in CABG outcomes: an independent risk factor or not, women are at a disadvantage. Thorac Cardiovasc Surg 2009;57:202-3.

33. Puskas JD, Kilgo PD, Kutner M, et al. Off-pump techniques disproportionately benefit women and narrow the gender disparity in outcomes after coronary artery bypass surgery. Circulation 2007;116:1192-9.

34. Lempereur M, Magne $\mathrm{J}$, Cornelis $\mathrm{K}$, et al. Impact of gender difference in hospital outcomes following percutaneous coronary intervention. Results of the Belgian Working Group on Interventional Cardiology (BWGIC) registry. Eurolntervention. Published Online First: 23 Dec 2014. doi:10.4244/EIJY14M12_11.

35. Song HK, Grab JD, O'Brien SM, et al. Gender differences in mortality after mitral valve operation: evidence for higher mortality in perimenopausal women. Ann Thorac Surg 2008;85:2040-4; discussion 5.

36. Sardar MR, Badri M, Prince CT, et al. Underrepresentation of women, elderly patients, and racial minorities in the randomized trials used for cardiovascular guidelines. JAMA Intern Med 2014;174:1868-70.

37. Hillis LD, Smith PK, Anderson JL, et al. 2011 ACCF/AHA Guideline for Coronary Artery Bypass Graft Surgery: a report of the American College of Cardiology Foundation/American Heart Association Task Force on Practice Guidelines. Circulation 2011;124:e652-735.

38. Annual Population Estimates. North Central Texas Council of Governments. April 2015. http://www.nctcog.org/ris/

39. Gijsberts CM, Gohar A, Ellenbroek GH, et al. Severity of stable coronary artery disease and its biomarkers differ between men and women undergoing angiography. Atherosclerosis 2015;241:234-40. 